\title{
DESIGN AND EVALUATION OF POLYMERIC CONTROLLED RELEASE NATAMYCIN OCULAR INSERTS
}

\author{
${ }^{1}$ A. Rajasekaran ${ }^{*},{ }^{2}$ V. Sivakumar, ${ }^{1}$ K. Karthika, ${ }^{1}$ J. Padma Preetha, ${ }^{1}$ T. Abirami \\ ${ }^{1} \mathrm{KMCH}$ College of Pharmacy, Kalapatti road, Coimbatore, India \\ ${ }^{2}$ Arulmigu Kalasalingam College of pharmacy, Krishnan coil, India \\ * Correspondence author: rsekaran2001in@yahoo.co.in \\ Received 9 September, 2009; Revised 13 January, 2010
}

\begin{abstract}
The main aim of this study is to develop ocular drug delivery system for Natamycin; a polyene antibiotic is highly useful for the treatment of conjunctivitis and keratitis. The ocuserts were prepared using different polymers such as eudragit L-100, eudragit S-100, eudragit RL-100, hydroxy propyl methyl cellulose phthalate and cellulose acetate phthalate at various proportion and combinations using PEG-400 as plasticizer. The prepared ocuserts were evaluated for their physicochemical parameters like drug content, weight uniformity, folding endurance, thickness, $\%$ moisture absorption and water vapour transmission rate. The in vitro drug release from the formulations was studied using commercial semi permeable membrane and the in vitro release kinetic datas were treated according to the diffusion models proposed by Higuchi and Peppas in order to access the mechanism of drug release from the formulations, which were following zero order kinetics. All the formulations showed no change in the physical appearance and the FTIR studies indicated no possibility of interaction between drug and polymer. The expected zero order release for one day was observed in the formulation D1 (3\% Eudragit RL100 and 1\% Eudragit L100)
\end{abstract}

Keywords: Ocular Insert, Ocular Delivery, Natamycin

\section{INTRODUCTION}

Amongst the various routes of drug delivery, the field of ocular drug delivery is one of the most interesting and challenging endeavors facing the pharmaceutical scientist for past 10-20 years ${ }^{1}$. As an isolated organ, eye is very difficult to study from a drug delivery point of view. Despite this limitation, improvements have been made with the objective of maintaining the drug in the biophase for an extended period ${ }^{2}$. Natamycin is a polyene antibiotic, poorly absorbed from the gastrointestinal tract, whose half life $\left(\mathrm{t}_{1 / 2}\right)$ of 2-3 h, low molecular weight, and non irritant nature make this a suitable candidate for administration by the ophthalmic route as a sustained release insert. It can be used in the treatment of conjunctivitis and keratitis by reducing intraocular pressure. It is presently available as eye drops but has several drawbacks like loss of drug by tear and lachrymal fluid, frequent administration and poor bioavailability ${ }^{3,4}$. In this study, an attempt was made to prepare as matrix diffusion controlled ocuserts with the target of increasing the contact time, reducing the frequency of administration, obtaining greater therapeutic efficiency, avoiding the pulsed type of dosing and improving patient compliance ${ }^{5}$.

\section{MATERIALS AND METHODS}

Natamycin was obtained from Desosa Pharmaceuticals Ltd. Mumbai, Eudragit L-100, Eudragit S100 were obtained from FDC Ltd., Mumbai, Eudragit RL-100 from Rolex Laboratory Reagent, Hydroxy propyl methyl cellulose phthalate from Pharma Fabrikan, Madurai and Cellulose acetate phthalate from Reachem Laboratory Chemical 
Fabrication of Natamycin Ocuserts: The matrix diffusion controlled ocuserts were prepared by solvent casting technique ${ }^{6}$. Among the various substrates for film formation including mercury, teflon, glass and aluminium mercury surface was found to give best results ${ }^{7}$. All further work was done using this substrate with a ring of $5.5 \mathrm{~cm}$ diameter having $7 \mathrm{ml}$ capacity. Accurately weighed quantities of $165.32 \mathrm{mg}$ of Natamycin and EUD L-100 were mixed with various polymers (EUDS100, HPMCP, EUD RL100 (or) CAP) using ethanol and acetone as solvents in 1:1 proportion. The bubble-free medicated solution was transferred quantitatively to the glass rings kept on the surface of mercury in petri plates. The petri plates were covered with inverted funnels to allow controlled evaporation of the solvent. These were left undisturbed in room temperature for two to three days. After complete drying, the film could be retrieved intact by slowly lifting the rings from the mercury substrate. Circular patches of $1 \mathrm{~cm}$ diameter, each containing $5.46 \mathrm{mg}$ of drug were cut and taken for evaluation studies.

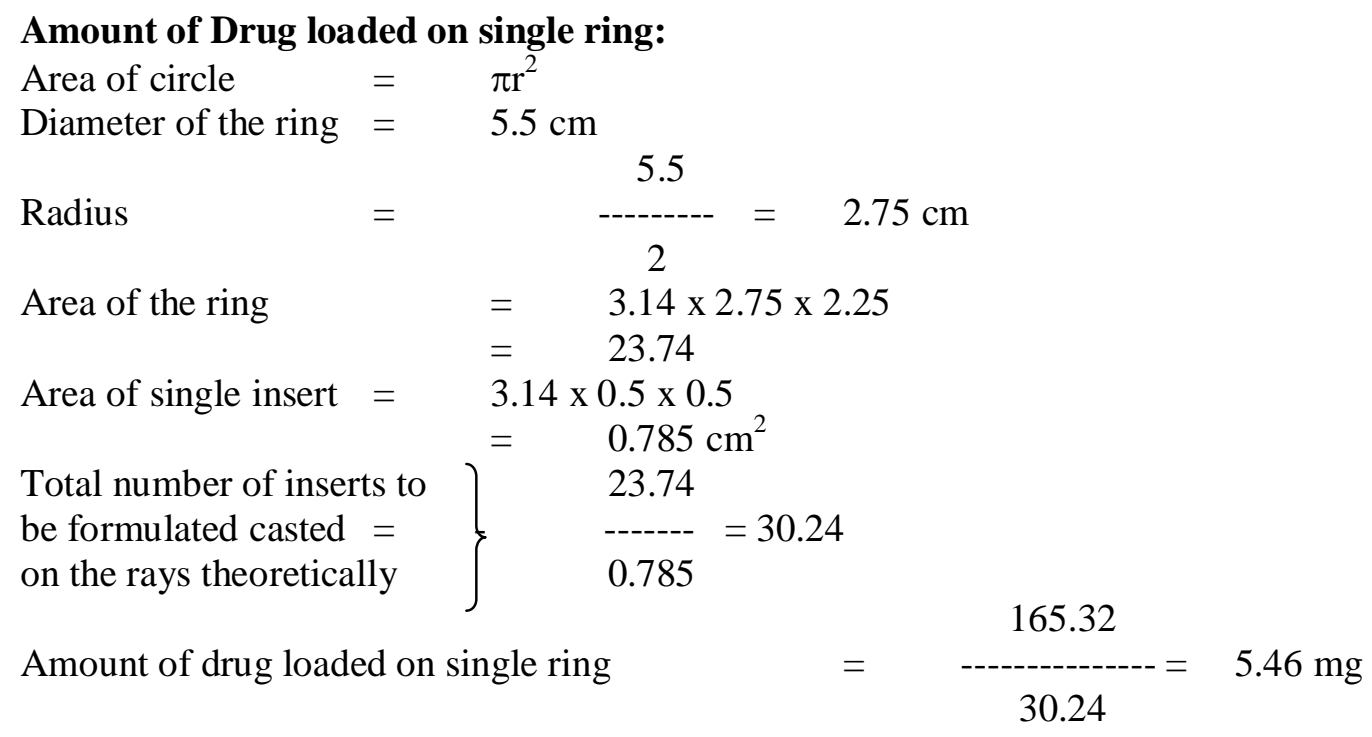

Evaluation of natamycin ocuserts: The prepared ocuserts were evaluated for their physicochemical parameters like drug content ${ }^{8}$, weight uniformity, folding endurance ${ }^{9}$, thickness, $\%$ moisture absorption $^{9}$ and $\%$ moisture loss ${ }^{9}$.

Thickness: Film thickness was measured by a screw gauge at three different points on the film ${ }^{7}$.

Weight uniformity: Each film was weighed individually, then the average weight of films taken as the weight of the film ${ }^{7}$.

Folding Endurance: Folding Endurance of the film was determined by repeatedly folding the inserts at the same place till it breaks ${ }^{7}$.

Percentage moisture loss: The ocuserts were weighed accurately and kept in a desiccators containing anhydrous calcium chloride. After 3 days, the films were taken out and weighed ${ }^{9}$.

Percentage moisture loss $=$

Initial weight- Final weight

Initial weight


Percentage moisture absorption: The ocuserts were preweighed accurately and kept in desiccators containing $100 \mathrm{ml}$ of saturated solution of aluminium chloride. After 3 days, the films were taken out and weighed ${ }^{9}$.

Final weight- Initial weight
Percentage moisture absorption=--yon
Initial weight

Drug content uniformity: The ocuserts of each formulation were cut into smaller pieces, placed in media and stirred by using mechanical stirrer. From this, samples were taken and drug content was analyzed by U.V Spectrophotometer at $260 \mathrm{~nm}^{8}$.

Water vapor transmission: The vials of equal diameter were used as transmission cells were washed and dried. About $1 \mathrm{gm}$ of fused calcium chloride was taken in the cells and the films were fixed over the brim with the help of solvent. Then, the cells were weighed accurately and kept in a closed desiccators containing saturated solution of potassium chloride $(200 \mathrm{ml})$ and the cells taken out and weighed after $1,2,3,4,5,6$ and $7^{\text {th }}$ day of storage. Then, the water vapors transmitted were calculated by the following formula ${ }^{9}$.

$$
\text { WVT Rate }=\frac{\text { WL }}{\text { S }}
$$

W- Gm of water transmitted

L- Thickness of film

S- Exposed surface area of film

FTIR studies: Physical stability and drug integrity of the formulations were studied using FTIR spectrophotometer ${ }^{9}$. The intactness of the formulations was confirmed by IR studies on a Shimadzu (8400s) infrared spectrophotometer using $\mathrm{KBr}$ disc. The FTIR absorption peak of pure Natamycin at $3118 \mathrm{~cm}^{-1}, 3070 \mathrm{~cm}^{-1}, 2359 \mathrm{~cm}^{-1}, 1507 \mathrm{~cm}^{-1}, 1277 \mathrm{~cm}^{-1}, 1143 \mathrm{~cm}^{-1}, 965 \mathrm{~cm}^{-1}, 850 \mathrm{~cm}^{-1} \& 651 \mathrm{~cm}^{-1}$ were also observed in FTIR spectrum of all formulations which implies that there was no chemical interaction or bonding decomposition between drug and polymers.

Stability studies: The stability studies were performed by keeping the formulation D1at $4{ }^{\circ} \mathrm{C}, 37^{\circ} \mathrm{C}$ and $50^{\circ} \mathrm{C}$. The drug content and its physical appearance were checked after 7,15,30,60 days by above mentioned methods ${ }^{9}$. Also, the sterility was checked in thioglycolate medium for UV sterilized films compared with unsterilized films ${ }^{6}$.

In vitro release studies through artificial membrane: The in vitro release studies were carried out using a bichambered donor-receiver compartment model designed using commercial semi permeable membrane of transparent and regenerated cellulose type (Sigma Dialysis Membrane) ${ }^{\mathbf{1 0}, \mathbf{1 1}}$. It was tied at one end of the open-end cylinder which acted as the donor compartment. The ocusert was placed inside the donor compartment. The semi permeable was used to simulate ocular in vivo conditions like corneal epithelial barrier. The tear volume was maintained with the help of $0.7 \mathrm{ml}$ distilled water. The entire surface of the membrane was in contact with the receptor compartment containing $25 \mathrm{ml}$ of distilled water. The content of the receptor compartment was stirred continuously using a magnetic stirrer. $1 \mathrm{ml}$ samples were withdrawn from the receptor compartment at periodic intervals and automatically replaced by equal volume of distilled water. The drug content was analyzed at $260 \mathrm{~nm}$ against reference standard using distilled water as blank on a Shimadzu UV/VisSpectrophotometer 


\section{RESULTS AND DISCUSSION}

In the present study, efforts were taken for designing and evaluating Natamycin ocular inserts. Natamycin, a polyene antibiotic is highly useful for the treatment of fungal blepharitis, conjunctivitis and keratitis. Natamycin when formulated as eye drops suffered the disadvantage of instillation of the dye drops for every 3-4 $\mathrm{h}$ and hence maximized patient non compliance, leading to ineffective therapy. In the current study, Natamycin ocusert was formulated using various polymers such as EUDL100, EUDS100, EUD RL100, CAP, and HPMCP by mercury surface casting technique using PEG 400 as plasticizer. The drug delivery system was designed as a matrix and the release was controlled by using different polymers. The datas from Table 1 indicates that the percentage of moisture absorption was more in the formulation C1 (3\% HPMCP, 1\% EUDL100). This may be due to the hydrophilic nature of HPMCP while the ocular insert D1 (3\% EUD RL100, 1\% EUDL100) showed minimum percentage of moisture absorption due to the hydrophobic nature of the later. The content uniformity of the drug was reproducible and within the limit. Thickness of the ocuserts varies between $0.04 \pm 0.02 \mathrm{~cm}$ to $0.06 \pm 0.01 \mathrm{~cm}$. The formulations are not very thicker and donor produces any irritation while placing in the cul-de-sac. The minimum standard deviation values revealed the fact that process used in the study is capable of giving films of uniform magnitude. This fact is further confirmed by drug content analysis data. The content uniformity of the drug was reproducible and within the limit. The weight of each ocusert ranged from $15.60 \pm 0.06 \mathrm{mg}$ to19.8 $\pm 0.52 \mathrm{mg}$. All the formulations were found to be in the limits and there was no significant deviation in the formulations. The folding endurance was measured for all formulations manually and the patches did not show any crack up to 300 folding and this indicates the good film forming property for all the polymers (Table 2).

Table 1: Formulation of Ocular Inserts of Natamycin

\begin{tabular}{|c|c|c|c|c|c|c|c|}
\hline \multirow{2}{*}{ Formulation code } & Drug & EUD.L-100 & EUD.S-100 & CAP & HPMCP & EUD RL-100 & Plasticizer (\% w/w) \\
\hline A1 & $165.32 \mathrm{mg}$ & $1 \%$ & $3 \%$ & - & - & - & PEG 400 \\
\hline A2 & $"$ & $2 \%$ & $2 \%$ & - & - & - & 33.33 \\
\hline A3 & $"$ & $3 \%$ & $1 \%$ & - & - & - & 33.33 \\
\hline B1 & $"$ & $1 \%$ & - & $3 \%$ & - & - & 33.33 \\
\hline B2 & $"$ & $2 \%$ & - & $2 \%$ & - & - & 33.33 \\
\hline B3 & $"$ & $3 \%$ & - & $1 \%$ & - & - & 33.33 \\
\hline C1 & $"$ & $1 \%$ & - & - & $3 \%$ & - & 33.33 \\
\hline C2 & $"$ & $2 \%$ & - & - & $2 \%$ & - & 33.33 \\
\hline C3 & $"$ & $3 \%$ & - & - & $1 \%$ & - & 33.33 \\
\hline D1 & $"$ & $1 \%$ & - & - & - & $3 \%$ & 33.33 \\
\hline D2 & $"$ & $2 \%$ & - & - & - & $2 \%$ & \\
\hline
\end{tabular}

A1 to D3 represent various formulations prepared using Eudragit S-100,Eudragit L-100, Hydroxy Propyl Methyl Cellulose phthalate as polymers and polyethylene glycol(PEG)400(33.33\% w/w of polymer) as plasticizer respectively. 
Table: 2 Evaluation of Physico-Chemical Parameters of Natamycin Ocuserts

\begin{tabular}{|c|c|c|c|c|c|c|c|c|}
\hline $\begin{array}{r}\text { Formulation } \\
\text { Code }\end{array}$ & 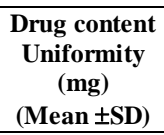 & $\begin{array}{c}\text { Weight } \\
\text { uniformity } \\
(\mathrm{mg}) \\
(\text { Mean } \pm \text { SD) }\end{array}$ & $\begin{array}{c}\text { Folding } \\
\text { endurance } \\
\text { (no } \pm \text { SD) }\end{array}$ & $\begin{array}{c}\text { Thickness } \\
(\mathbf{c m}) \\
(\mathrm{Mean} \pm \mathrm{SD})\end{array}$ & $\begin{array}{c}\text { Moisture } \\
\text { absorption } \\
(\% \pm \text { SD) }\end{array}$ & $\begin{array}{c}\text { Moisture } \\
\text { loss } \\
(\% \pm \text { SD }\end{array}$ & 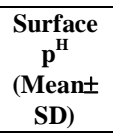 & $\begin{array}{c}\text { Water transmission } \\
\left(\text { Rate }^{2} \mathbf{1 0}^{-3}\right) \\
\text { mg.cm }{ }^{-2} h^{-1}(\text { Mean } \pm \\
\text { SD })\end{array}$ \\
\hline A1 & $5.20 \pm 0.06$ & $15.60 \pm 0.06$ & $187 \pm 1.22$ & $0.05 \pm 0.03$ & $3.38 \pm 0.02$ & $3.22 \pm 0.02$ & $6.8 \pm 0.05$ & $2.212 \pm 0.02$ \\
\hline A2 & $5.36 \pm 0.05$ & $16.04 \pm 0.71$ & $177 \pm 2.01$ & $0.05 \pm 0.01$ & $3.42 \pm 0.06$ & $3.20 \pm 0.06$ & $6.5 \pm 0.05$ & $2.208 \pm 0.05$ \\
\hline A3 & $4.92 \pm 0.06$ & $17.0 \pm 0.71$ & $165 \pm 1.62$ & $0.04 \pm 0.02$ & $3.48 \pm 0.05$ & $3.37 \pm 0.05$ & $6.5 \pm 0.03$ & $2.202 \pm 0.04$ \\
\hline B1 & $5.10 \pm 0.03$ & $18.2 \pm 0.59$ & $148 \pm 2.42$ & $0.04 \pm 0.02$ & $4.25 \pm 0.05$ & $4.20 \pm 0.05$ & $7.1 \pm 0.04$ & $2.215 \pm 0.05$ \\
\hline B2 & $4.80 \pm 0.05$ & $16.4 \pm 0.04$ & $152 \pm 1.03$ & $0.05 \pm 0.03$ & $4.11 \pm 0.03$ & $4.06 \pm 0.03$ & $7.3 \pm 0.05$ & $2.208 \pm 0.04$ \\
\hline B3 & $5.32 \pm 0.06$ & $17.3 \pm 0.05$ & $161 \pm 1.76$ & $0.05 \pm 0.02$ & $4.08 \pm 0.06$ & $4.01 \pm 0.06$ & $7.5 \pm 0.02$ & $2.204 \pm 0.06$ \\
\hline $\mathrm{C} 1$ & $5.44 \pm 0.05$ & $18.6 \pm 0.01$ & $164 \pm 0.88$ & $0.04 \pm 0.02$ & $5.10 \pm 0.05$ & $5.02 \pm 0.05$ & $7.8 \pm 0.08$ & $1.548 \pm 0.05$ \\
\hline $\mathrm{C} 2$ & $5.36 \pm 0.06$ & $19.8 \pm 0.52$ & $162 \pm 1.23$ & $0.05 \pm 0.03$ & $5.06 \pm 0.02$ & $4.90 \pm 0.02$ & $6.8 \pm 0.05$ & $1.542 \pm 0.06$ \\
\hline $\mathrm{C} 3$ & $4.84 \pm 0.03$ & $16.7 \pm 0.63$ & $158 \pm 0.92$ & $0.05 \pm 0.02$ & $5.02 \pm 0.08$ & $4.92 \pm 0.08$ & $6.5 \pm 0.08$ & $1.538 \pm 0.07$ \\
\hline D1 & $5.28 \pm 0.04$ & $15.1 \pm 0.65$ & $192 \pm 0.61$ & $0.06 \pm 0.01$ & $3.32 \pm 0.07$ & $3.22 \pm 0.07$ & $6.8 \pm 0.03$ & $1.522 \pm 0.02$ \\
\hline D2 & $4.96 \pm 0.05$ & $17.4 \pm 0.67$ & $184 \pm 0.53$ & $0.05 \pm 0.03$ & $3.36 \pm 0.06$ & $3.26 \pm 0.06$ & $7.1 \pm 0.03$ & $1.515 \pm 0.06$ \\
\hline D3 & $5.66 \pm 0.04$ & $18.3 \pm 0.68$ & $178 \pm 1.22$ & $0.05 \pm 0.02$ & $3.48 \pm 0.04$ & $3.38 \pm 0.04$ & $7.5 \pm 0.04$ & $1.510 \pm 0.03$ \\
\hline
\end{tabular}

All the formulations were subjected to evaluate the surface $\mathrm{pH}$; they had $\mathrm{pH}$ near to neutral $\mathrm{pH}$ and hence will not create any difficulty or irritation while placing in the cul-de-sac of the eye. The water vapour transmission studies were also conducted to find out the order of hydrophilicity of the polymers which showed that the insert containing CAP and HPMCP exhibited maximum water vapour transmission and the order of hydrophilicity of the polymers used in the study is as follows CAP > HPMCP > EUD S100 > EUD RL100. This can be attributed to the higher affinity, solubility and low viscosity of CAP which altogether contributed to maximum water absorption and transfer characteristics. Similarly least affinity for water due to hydrophobic molecular substitutions might have contributed to the least moisture absorption and transfer characteristics of EUD RL 100 (Table 2) 
Table: 3 Data showing the different parameters of natamycin ocuserts after stability studies

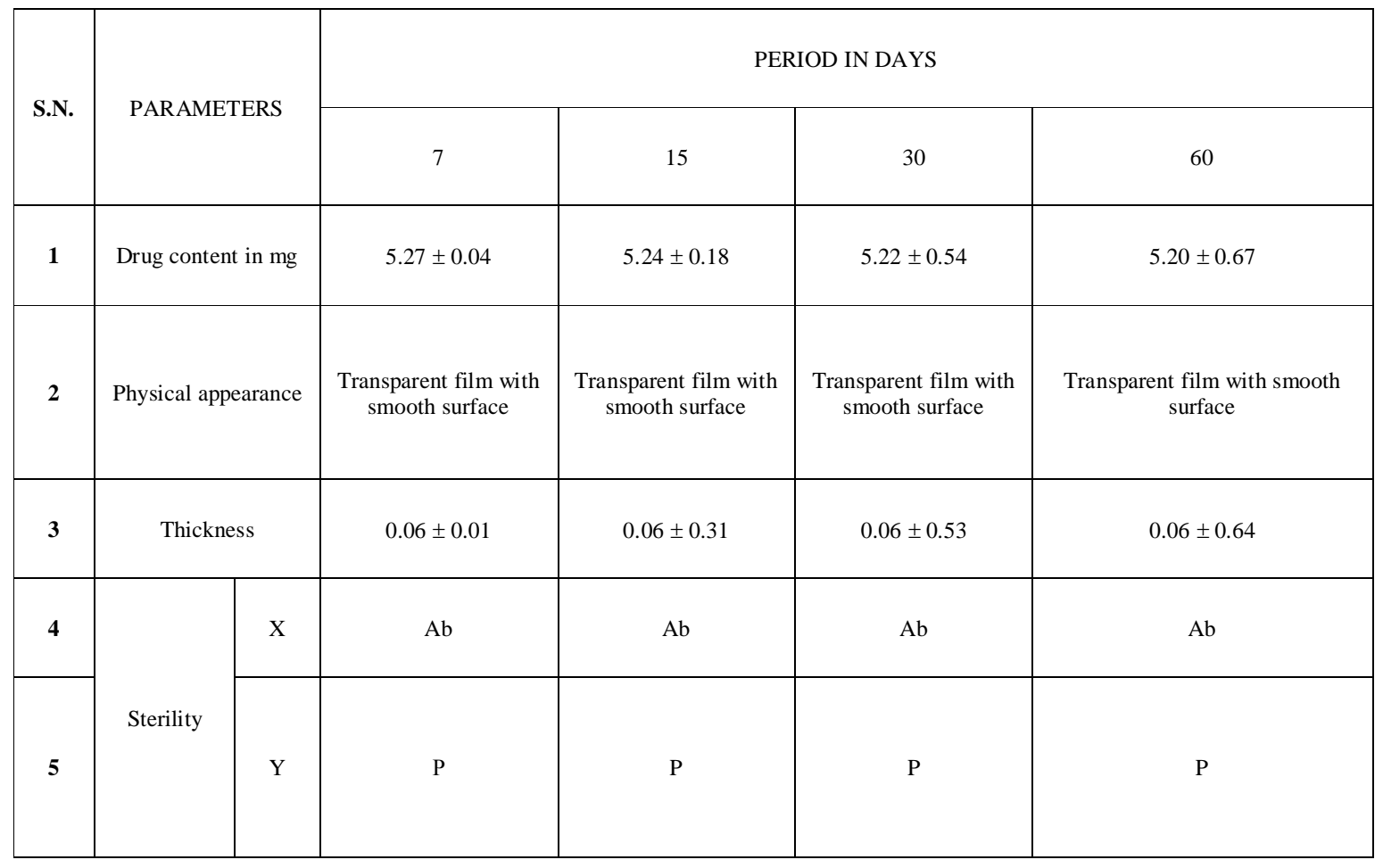

X-Surface Sterilized Film, Y-Unsterilized Film, Ab-Absence of Microbial Growth, P-Presence of Microbial Growth

The In vitro release studies for the formulations were given in the Table 4. Data revealed that the ocular inserts prepared with CAP, HPMCP, EUD S100 were found to be devoid of drug molecule within 10-15 hrs but inserts designed using increasing concentration of EUD RL100 (D3, D2, D1) showed a maximum release of up to 18 to $23 \mathrm{hrs}$ and the required drug release was achieved from formulation D1 (3\%EUDRL100, \% EUD L100) over an extended period of $23 \mathrm{hrs}$. Though, some other formulations had shown the zero order release, the amount of drug released was less when compared to $\mathrm{D} 1$. This may be due to the $\mathrm{pH}$ independent releasing nature of the polymer and also the increased hydrophobicity of the same. The in-vitro kinetic data were graphically treated according to zero and first order equation to elucidate the mode of release. They were also treated for Higuchi's equation and peppa's equation to conform the mechanism of drug release ${ }^{8}$. Graphical best fit for the afore mentioned models were done and regression analysis was carried out to ensure the authenticity of best fit and the regression values for the graphical fit calculated were shown in the Table 3 . From the results, it was concluded that the drug release from the ocular inserts followed zero order kinetics and the release of the drug from the matrix followed Higuchi's equation. 
Table: 4 In vitro release studies through artificial membrane- sigma dialysis membrane

\begin{tabular}{|c|c|c|c|c|c|c|c|c|c|c|c|c|}
\hline \multirow{2}{*}{$\begin{array}{l}\text { TIME IN } \\
\text { HOURS }\end{array}$} & \multicolumn{12}{|c|}{ CUMULATIVE \% OF DRUG RELEASE OF NATAMYCIN OCUSERTS } \\
\hline & A1 & A2 & A3 & B1 & B2 & B3 & $\mathrm{C} 1$ & $\mathrm{C} 2$ & $\mathrm{C} 3$ & D1 & D2 & D3 \\
\hline 0 & 0 & 0 & 0 & 0 & 0 & 0 & 0 & 0 & 0 & 0 & 0 & 0 \\
\hline 2 & 31.7 & 35.3 & 40.2 & 32.6 & 31.4 & 25.4 & 22.1 & 19.7 & 14.7 & 10.8 & 11.8 & 13.5 \\
\hline 4 & 46.8 & 51.6 & 62.5 & 44.5 & 42.5 & 36.6 & 35.6 & 32.5 & 28.8 & 25.5 & 31.5 & 34.6 \\
\hline 6 & 58.6 & 63.7 & 86.4 & 64.8 & 61.5 & 46.2 & 46.7 & 43.6 & 39.6 & 38.9 & 42.8 & 44.3 \\
\hline 8 & 77.4 & 80.6 & 98.3 & 82.2 & 76.4 & 66.6 & 55.7 & 51.4 & 45.8 & 43.6 & 47.8 & 51.5 \\
\hline 10 & 85.7 & 95.9 & & 98.6 & 84.5 & 78.4 & 64.6 & 62.4 & 58.7 & 50.7 & 53.8 & 61.4 \\
\hline 12 & 99.2 & & & & 97.9 & 85.3 & 70.9 & 68.9 & 64.5 & 59.8 & 62.5 & 69.7 \\
\hline 14 & & & & & & 96.7 & 82.6 & 79.5 & 76.4 & 65.8 & 69.7 & 77.5 \\
\hline 16 & & & & & & & 98.9 & 90.6 & 80.5 & 72.5 & 75.6 & 84.3 \\
\hline 18 & & & & & & & & 96.4 & 85.9 & 78.6 & 86.4 & 98.6 \\
\hline 20 & & & & & & & & & 98.5 & 89.5 & 97.8 & \\
\hline 21 & & & & & & & & & & 94.6 & & \\
\hline 22 & & & & & & & & & & 98.5 & & \\
\hline
\end{tabular}

\section{CONCLUSION}

It is concluded from the present studies that the ocuserts of natamycin are capable of exhibiting controlled drug release with ideal sterility and stability and the formulation D1 (EUD RL100 3\%, EUD L100 1\%) has fulfilled the objectives of the present studies. Since, it released the drug with the fair correlation of 0.9923 and also retarded the release of the drug from the matrix until $21 \mathrm{hrs}$ because of the $\mathrm{pH}$ Independent permeability of the Eudragit RL100. Hence the formulation D1 may produce fruitful results to the patients and may create patient compliance.

\section{REFERENCES}

1. Jain M K, Manqué S A \& Deshpande S G, 2005. Controlled and Novel Drug Delivery, CBS publishers, New Delhi, $1^{\text {st }}$ Edition, 82-96.

2. Manoj A B, 1993. Topical ocular drug delivery review, Indian drugs 4, 51.

3. Venkateshwar Rao, Somashekar Shyale, 2004. Preparation and Evaluation Of Ocular Inserts Containing Norfloxacin, Turkey Journal of Medical Science, 34, 239-246. 
4. Manvi F V, Nanjwade B K, Hiremath S P \& Chalikwar S S, 2004. Formulation and Evaluation of Diclofenac Sodium Ophthalmic Inserts, The Eastern Pharmacist, 25, 55-57.

5. Marco Fabrizio S, Lotta S, 1995. Ocular inserts for Topical delivery, Advanced Drug Delivery Reviews, 16, 95-106.

6. Vijayendra Swamy.S.M, Nanjawade B.K, 2006. Development of Sustained Ocular Drug Delivery System For Betaxolol, 40(3), 165-168.

7. Abhilash A S, Jaya Prakash S, Nagarajan M. \& Dhachina Moorthy D., 2005. Design and evaluation of timolol maleate ocuserts, Ind.J.Pharm.Sci. 67(3), 311-314.

8. Manvi F.V., Soppimath K.S. and Gadad A.P., 1997. Development and evaluation of Timolol maleate ocular inserts., Indian drugs, 34(5), 264-268.

9. Deoa.J.Khopade M R \& Jain N K, 1997. Development Of Liquid Crystalline Proliposomal Gel For Sustained Ophthalmic Drug Delivery,Indian drugs, 34(5), 252-257.

10. Saisivam R. Vijay Muthu Manikandar R \& Nagarajan KM, 1999. Designed And Evaluated Ciprofloxacin Hydro Chloride Ocuserts, Ind.J.of.Pharn.Sci.61(1), 34-38.

11. Maria G R, Jayapraksh S, 2001. Design and Evaluation Of Polymeric Ocular Drug Delivery System for Controlled Release of Tetracycline, Indian J.Pharm.Sci. 10, 526- 528. 